\title{
$S$-1-Propenylcysteine, a sulfur compound in aged garlic extract, alleviates cold-induced reduction in peripheral blood flow in rat via activation of the AMPK/eNOS/NO pathway
}

\author{
MITSUYASU USHIJIMA, KAYO KUNIMURA and JUN-ICHIRO SUZUKI
}

Central Research Institute, Wakunaga Pharmaceutical Co., Ltd., Hiroshima 739-1195, Japan

Received June 11, 2020; Accepted July 7, 2020

DOI: $10.3892 / \mathrm{etm} .2020 .8969$

\begin{abstract}
Aged garlic extract (AGE) has been shown to improve peripheral circulatory disturbances in both clinical trials and experimental animal models. To investigate the effect of $S$-1-propenylcysteine (S1PC), a characteristic sulfur compound in AGE, on cold-induced reduction in tail blood flow of rat, Wistar rats were individually placed in a restraint cage and given the treatment with cold water $\left(15^{\circ} \mathrm{C}\right)$ after the oral administration of AGE or its constituents S1PC, $S$-allylcysteine (SAC) and $S$-allylmercaptocysteine (SAMC). After the cold-treatment the tail blood flow of rats was measured at the indicated times. The pretreatment with AGE ( $2 \mathrm{~g} / \mathrm{kg} \mathrm{BW})$ and S1PC $(6.5 \mathrm{mg} / \mathrm{kg} \mathrm{BW})$ significantly alleviated the reduction of rat tail blood flow induced by cold treatment. The effect of S1PC was dose-dependent and maximal at the dose of $6.5 \mathrm{mg} / \mathrm{kg} \mathrm{BW}$, whereas SAC and SAMC were ineffective. To gain insight into the mechanism of S1PC action, the concentration of nitrogen oxide metabolites (NOx) in the plasma and the levels of phosphorylated endothelial nitric oxide synthase (eNOS) and 5'-AMP-activated protein kinase (AMPK) in the aorta were measured. The pretreatment with S1PC significantly increased the plasma concentration of NOx as well as the level of phosphorylated form of AMPK and eNOS in the aorta after cold-treatment. The present findings suggest that S1PC is a major constituent responsible for the effect of AGE to alleviate the cold-induced reduction of peripheral blood flow in rat by acting on the AMPK/eNOS/NO pathway in the aorta.
\end{abstract}

\section{Introduction}

Blood circulation plays a fundamental role in the body homeostasis by supporting the critical functions including the transport of water, oxygen, nutrients, and hormones as well as carbon dioxide and metabolic waste from cells for removal.

Correspondence to: Dr Mitsuyasu Ushijima, Central Research Institute, Wakunaga Pharmaceutical Co., Ltd., 1624 Shimokotachi, Koda-cho, Akitakata-shi, Hiroshima 739-1195, Japan

E-mail: ushijima_m@wakunaga.co.jp

Key words: aged garlic extract, $S$-1-propenylcysteine, peripheral blood flow, cold exposure, AMPK/eNOS/NO pathway
With the change of modern lifestyle, people suffer from chilliness due to mental stress (1) and excessive use of air-conditioning systems (2). Raynaud's phenomenon (RP) is a disease caused by vasoconstriction of cutaneous arterioles induced by cold exposure and mental stress and is accompanied by such characteristic symptoms as cold sensation in the limbs, pain, numbness, swelling, and digital ulcers $(3,4)$. Current pharmacological treatments including calcium channel blockers, phosphodiesterase type 5 inhibitors, intravenous prostanoids, and topical nitrates fail to completely control RP and are not well tolerated by some patients (4).

Aged garlic extract (AGE) is a unique garlic product prepared through long extraction processes with water-ethanol for more than 10 months (5). During this period, many harsh and strong odor substances (i.e., allicin) in raw garlic are converted into non-irritating water-soluble sulfur-containing amino acids such as $S$-allylcysteine (SAC), $S$-1-propenylcysteine (S1PC), and $S$-allylmercaptocysteine (SAMC) $(6,7)$.

Previous studies have demonstrated the beneficial effect of AGE on hypertension (8-12), atherosclerosis (13-15), metabolic syndrome (16), and gingivitis (17). Furthermore, recent studies have revealed that AGE and its constituents, SAC and S1PC, exert such desirable effects as anti-hypertension (18-22), cardioprotection (23), antioxidation (24-27), antiaging $(27,28)$, immunomodulation (29-31), anti-fatigue $(32,33)$, anti-stress (34,35), anti-inflammation (36-39), and liver protection (40).

Several previous studies show that AGE improves the peripheral circulatory disturbances. One clinical study using thermography demonstrated that AGE supplementation increases microcirculation and improves a variety of symptoms in patients (41). In another clinical study, AGE has been shown to enhance cutaneous microcirculation in patients with the increased risk of cardiovascular events (42). In addition, an animal study demonstrated that AGE can reverse the decrease in the rectal temperature of mice induced by cooling $(32,43)$. Furthermore, administration of S1PC, a characteristic constituent of AGE increased the blood flow of tail skin in spontaneously hypertensive rats (SHR) (21).

The above reports indicate that AGE is effective in improving the peripheral circulation in both animal and human. At present, however, the mechanism whereby AGE improves the circulation remains unclear. Hence, this study 
was conducted with the aim to identify the active constituent of AGE and to clarify its mechanism of action using the model of cold-induced reduction in the tail blood flow of rat.

\section{Materials and methods}

Chemicals. AGE was prepared from cloves of garlic (Allium sativum $\mathrm{L}$.) through the process of rinsing with purified water, slicing, soaking in ethanol $20-50 \%(\mathrm{v} / \mathrm{v})$, and extraction/aging for more than 10 months (5). S1PC was isolated and purified from AGE using preparative high-performance liquid chromatography (HPLC), as previously reported (7). SAC and SAMC were synthesized according to previous methods (7). Chemicals for synthesis of compounds and post-column HPLC detection reagents were obtained from Tokyo Chemical Industry. Solvents for HPLC were purchased from Wako Pure Chemicals Industry. Authentic sulfur compounds for identification were synthesized and purified according to the previous report (7).

HPLC analysis. HPLC analysis was performed by post-column HPLC using a NEXERA X2 system (Shimadzu, Kyoto, Japan) according to the previous report (7). The column utilized for separation was a Cadenza CD-C18 column $(2.0 \times 150 \mathrm{~mm}$, $3 \mu \mathrm{m}$; Imtakt Corporation). The sulfur compounds were derivatized with the hexaiodoplatinate reagents (Tokyo Chemical Industry) and detected at $500 \mathrm{~nm}$ absorbance using diode array detector.

Animals and test substances. Specific pathogen-free male Wistar rats were obtained at the age of 7 weeks from Japan SLC, Inc (Shizuoka, Japan). Rats were kept at $23 \pm 3^{\circ} \mathrm{C}$ and $50 \pm 10 \%$ humidity under a 12 -h light-dark cycle (light 7:00 a.m.-7:00 p.m.), with free access to commercially available hard feed (CE-2) and water, until the experimental use at 10 to 14 -weeks of age. AGE was diluted at $0.2 \mathrm{~g} / \mathrm{ml}$ with distilled water (DW). SAC, S1PC, and SAMC were dissolved in DW. All test substances (AGE, SAC, S1PC, and SAMC) were administered to rats in a volume of $10 \mathrm{ml} / \mathrm{kg}$ BW using Teflon feeding needles. The control group was orally administered DW in a volume of $10 \mathrm{ml} / \mathrm{kg}$ BW. Animal experiments were approved by the Animal Care and Use Committee of Wakunaga Pharmaceutical Co., Ltd. (approval no. 258). This investigation conformed with the Guide for the Care and Use of Laboratory Animals published by the US National Institute of Health (NIH Publication, 8th edition, 2011).

Cold-induced model of reduced tail blood flow. The cold-induced model of peripheral circulation disorder was designed based on the rat cooling RP (44) and cold blood stasis syndrome models $(45,46)$. After being acclimatized to the experiment room at $23^{\circ} \mathrm{C}$ for at least $30 \mathrm{~min}$, rats were examined for skin blood flow before treatment and then orally administered test substances. Two hours later, the rats were placed in restrictive cages (KN-468-B; Natsume) for cooling and submersed in tank filled with $15^{\circ} \mathrm{C}$ water up to the xiphoid processes for $10 \mathrm{~min}$. In the case of non-cooling experiments, rats were placed in restrictive cages for $10 \mathrm{~min}$ without cooling. After being returned to rearing cages, the rats were examined for the tail blood flows $1 \mathrm{~h}$ after cooling.
Measurement of tail blood flow. The tail blood flow of rats was measured by using a contact laser Doppler blood flow meter (FLO-C1; Omegawave). Each rat was placed in a holder under anesthesia with isoflurane $(1 \mathrm{l} / \mathrm{min})$ and its tail blood flow was examined for $3 \mathrm{~min}$. The probe for the measurement was attached $5 \mathrm{~cm}$ apart from the base of the tail. Rats were cooled for $10 \mathrm{~min}$ at $2 \mathrm{~h}$ after administering AGE ( $2 \mathrm{~g} / \mathrm{kg} \mathrm{BW} ; \mathrm{n}=10)$ or S1PC (6.5 mg/kg BW; $\mathrm{n}=9)$, and then measured for their tail blood flows at 1, 2 and $3 \mathrm{~h}$ after cooling. For the comparison of the effect of three sulfur constituents, rats were orally administered SAC (7.9 mg/kg BW), SAMC (1.3 mg/kg BW), or S1PC $(0.26,1.3$ and $6.5 \mathrm{mg} / \mathrm{kg} \mathrm{BW})$, followed by cooling for $10 \mathrm{~min}$ at $2 \mathrm{~h}$ later. The tail blood flow was measured at $1 \mathrm{~h}$ after cooling $(\mathrm{n}=10)$. The dose of SAC ( $7.9 \mathrm{mg} / \mathrm{kg} \mathrm{BW})$, SAMC $(1.3 \mathrm{mg} / \mathrm{kg} \mathrm{BW})$, and S1PC $(6.5 \mathrm{mg} / \mathrm{kg} \mathrm{BW})$ was equivalent to the amount contained in AGE at $2 \mathrm{~g} / \mathrm{kg} \mathrm{BW}$. In another study, rats were also measured for their tail blood flow without cooling after oral administration of AGE $(2 \mathrm{~g} / \mathrm{kg} \mathrm{BW})$ or S1PC (6.5 mg/kg BW; $\mathrm{n}=6$ ).

Measurements of plasma NOx level and vascular NO-related phosphorylation. Rats were cooled for $10 \mathrm{~min}$ at $2 \mathrm{~h}$ after administration of S1PC $(6.5 \mathrm{mg} / \mathrm{kg} \mathrm{BW})$ or DW (control) and then anesthetized with isoflurane $(1 \mathrm{l} / \mathrm{min})$ to collect the blood from the orbital vein at $1 \mathrm{~h}$ after cooling. Another group of rats was administered DW and did not receive the cooling treatment (non-cooling control). After centrifugation of blood samples at $1,500 \mathrm{x}$ g for $15 \mathrm{~min}$ at $4^{\circ} \mathrm{C}$, plasma samples were obtained and stored at $-80^{\circ} \mathrm{C}$ until analysis. Thoracic aortas of rats were also isolated, frozen by liquid nitrogen, and stored at $-80^{\circ} \mathrm{C}$ until analysis. The plasma content of NOx was determined by using a NOx colorimetric assay kit (Cayman Chemical Company) according to the manufacturer's instructions. Rat thoracic aortas were homogenized using the Multi-Beads shocker (Yasui Kikai) and lysed by a RIPA lysis buffer (Merck $\mathrm{KGaA}$ ) containing Halt protease and phosphatase inhibitor (Thermo Fisher Scientific, Inc.). Western blot analysis of the lysates was performed as previously described (40). In brief, individual proteins were separated by SDS-PAGE and immunoblotted with an anti-phospho-eNOS (Ser1177; Cell Signaling Technology, Inc.), anti-eNOS (Santa Cruz Biotechnology, Inc.), anti-phospho-AMPK $\alpha$ (Thr172; Cell Signaling Technology, Inc.), anti-AMPK $\alpha$ (ProteinTech Group, Inc.), and anti-GAPDH antibody (Wako). Immunoreactive bands were visualized and analyzed on a V3 Western Workflow (Bio-Rad Laboratories, Inc.) using Image $\mathrm{Lab}^{\mathrm{TM}}$ software.

Statistical analysis. The data were expressed as mean \pm SEM. Statistically significant differences between test substance-treated and control DW-treated groups were determined using Student's t-test or one-way analysis of variance (ANOVA) followed by Bonferroni's multiple comparison test. $\mathrm{P}<0.05$ was considered to indicate a statistically significant difference. All statistical analyses were performed using WinSTAT (R. Fitch Software).

\section{Results}

Characterization of hydrophilic sulfur compounds in AGE. AGE used in this study was analyzed by post-column HPLC 
Table I. Characterization of hydrophilic sulfur compounds in aged garlic extract by post-column HPLC chromatogram.

\begin{tabular}{rcrl}
\hline \multicolumn{1}{l}{ Rt } & \multicolumn{1}{c}{ Mw } & Area $(\%)$ & \\
\hline 4.11 & Not determined & 1.29 & Compound \\
8.59 & Not determined & 0.12 & Unknown \\
10.57 & Not determined & 1.52 & Unknown \\
13.41 & Not determined & 1.36 & Unknown \\
24.15 & 149 & 3.52 & Unknown \\
25.71 & Not determined & 0.47 & Methionine \\
26.44 & 167 & 1.72 & Unknown \\
27.79 & Not determined & 0.67 & $S$-Methylmercaptocysteine \\
31.38 & 161 & 19.74 & Unknown \\
34.12 & 161 & 2.12 & $S$-Allylcysteine \\
34.97 & 161 & 14.81 & Cis-S-1-propenycysteine \\
37.66 & 290 & 16.37 & Trans- $S$-1-propenycysteine \\
40.97 & 175 & 21.09 & $\gamma$-Glutamyl- $S$-allylcysteine \\
42.00 & 193 & 8.24 & $S$-n-Butenylcysteine (internal standard) \\
49.24 & 322 & 6.98 & $S$-Allylmercaptocysteine \\
\end{tabular}

HPLC, high-performance liquid chromatography.

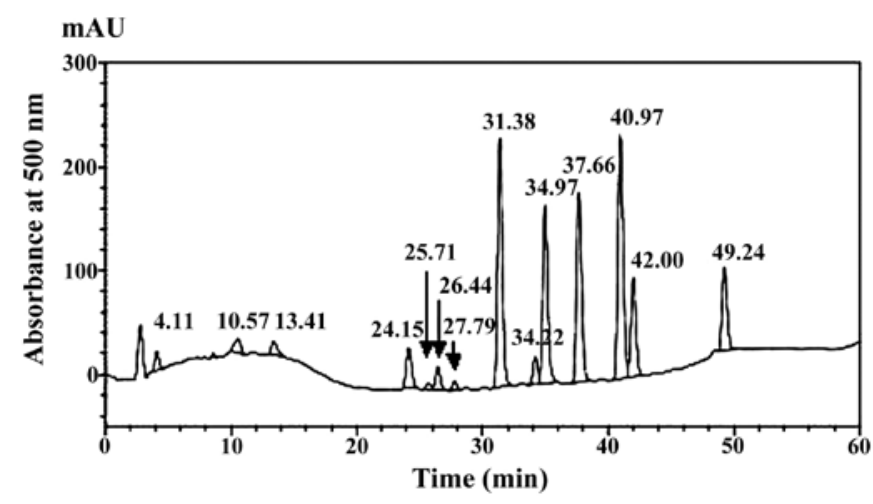

Figure 1. Chromatogram of hydrophilic sulfur compounds in AGE by post-column HPLC analysis. The chromatogram was monitored at $500 \mathrm{~nm}$ absorbance. AGE, aged garlic extract; HPLC, high-performance liquid chromatography.

using hexaiodoplatinate reagent for sulfur-specific detection (7). This analysis detected and identified 11 hydrophilic sulfur constituents such as S-methylcysteine, SAC, S1PC, and SAMC which are formed in AGE through the aging process (7) (Fig. 1 and Table I).

Effects of AGE and its constituents on tail blood flow. After cooling $\left(15^{\circ} \mathrm{C}, 10 \mathrm{~min}\right)$, the tail blood flow of DW-pretreated control rats decreased $53 \%$ at $1 \mathrm{~h}$, as compared to the non-cooling level $(\mathrm{P}<0.01)$, and then returned almost to the initial level at $3 \mathrm{~h}$ (Fig. 2). On the other hand, the tail blood flow of AGE (2 $\mathrm{g} / \mathrm{kg} \mathrm{BW})$-pretreated group was significantly $(\mathrm{P}<0.01)$ higher than that of $\mathrm{DW}$-pretreated control group after cooling and returned to almost initial non-cooling level (Fig. 2).

The effect of AGE constituents, SAC, S1PC, and SAMC, on the blood flow was also examined. As shown in Fig. 3, pretreatment with S1PC $(6.5 \mathrm{mg} / \mathrm{kg}$ BW $)$ significantly

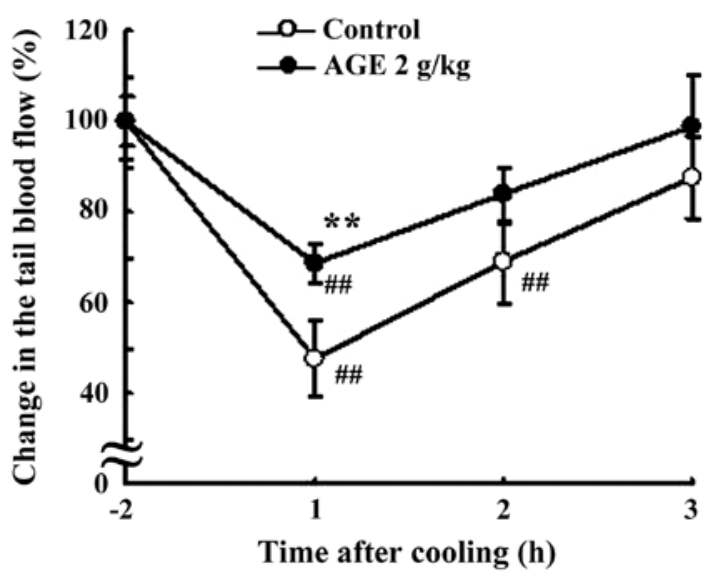

Figure 2. The effect of AGE pretreatment on the tail blood flow in cold-treated rats. AGE ( $2 \mathrm{~g} / \mathrm{kg} \mathrm{BW})$ was orally administered to male Wistar rats $2 \mathrm{~h}$ before cold-treatment. Distilled water $(10 \mathrm{ml} / \mathrm{kg} \mathrm{BW})$ was given to control group rats. Rats were cooled by submerging them up to the xiphoid in a tank filled with water at $15^{\circ} \mathrm{C}$ for $10 \mathrm{~min}$. The level of tail blood flow at $2 \mathrm{~h}$ before cooling is set to $100 \%$. Data are shown as the means \pm SEM $(\mathrm{n}=9) .{ }^{* *}$ Denotes the significant difference, compared with the control group $(\mathrm{P}<0.01)$. "\# Denotes the significant difference compared with the level before cooling $(\mathrm{P}<0.01)$. AGE, aged garlic extract.

$(\mathrm{P}<0.05)$ improved the reduction in the tail blood flow compared to the pretreatment with DW (control) at $1 \mathrm{~h}$ after cooling. However, pretreatment with SAC or SAMC showed no significant improvement. As shown in Fig. 4, the effect of S1PC is dose-dependent: and the dose of S1PC $6.5 \mathrm{mg} / \mathrm{kg} \mathrm{BW}$ produced a larger increase of tail blood flow. Fig. 5 showed the time course pattern of tail blood flow in the S1PC $(6.5 \mathrm{mg} / \mathrm{kg} \mathrm{BW})$-pretreated group after cooling. At $1 \mathrm{~h}$ after cooling, tail blood flow was significantly higher $(\mathrm{P}<0.05)$ in the S1PC-pretreated group than in the DW-pretreated control group. Thereafter, no significant difference was observed in the tail blood flow between the two groups. Both S1PC and 
Table II. The effect of S1PC on the plasma concentration of NOx in cold-treated rats.

Group

No cold treatment

Plasma NOx concentration $(\mu \mathrm{M})$

Cold treatment only

$2.95 \pm 0.57^{\mathrm{b}}$

S1PC pretreatment and

$6.57 \pm 0.60$

cold treatment

Distilled water $(10 \mathrm{ml} / \mathrm{kg} \mathrm{BW})$ or S1PC at the dose of $6.5 \mathrm{mg} / \mathrm{kg} \mathrm{BW}$ was orally administered to male Wistar rats $2 \mathrm{~h}$ before cold-treatment $\left(15^{\circ} \mathrm{C}, 10 \mathrm{~min}\right.$.). The NOx concentration in the plasma was measured $1 \mathrm{~h}$ after the cold-treatment. Data are shown as the means \pm SEM $(\mathrm{n}=9-10)$. The ${ }^{\mathrm{a}}$ and ${ }^{\mathrm{b}}$ denote the significant difference $(\mathrm{P}<0.05$ and $\mathrm{P}<0.01$, respectively) compared with the cold-treated group. NOx, nitrogen oxide metabolites; S1PC, $S$-1-propenylcysteine.

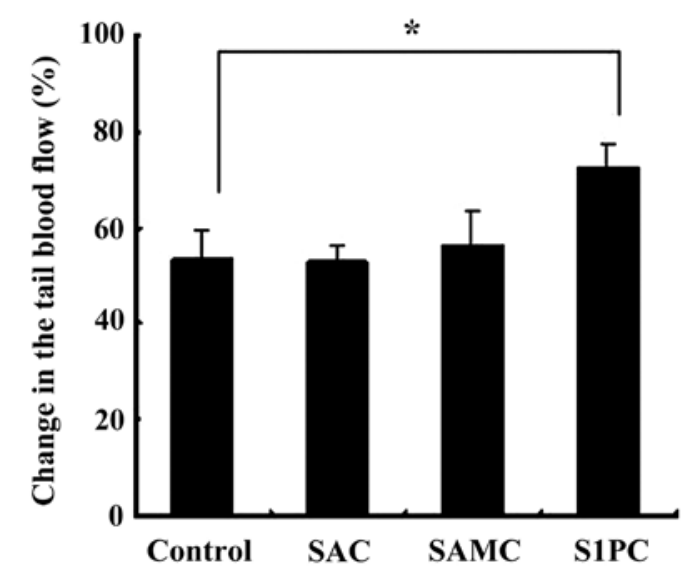

Figure 3. The effect of pretreatment with of SAC, SAMC, and S1PC on the tail blood flow in cold-treated rats. SAC, SAMC, and S1PC were orally administered at the dose of $7.9,1.3$ and $6.5 \mathrm{mg} / \mathrm{kg} \mathrm{BW}$, respectively, to male Wistar rats $2 \mathrm{~h}$ before cold-treatment $\left(15^{\circ} \mathrm{C}, 10 \mathrm{~min}\right)$. Distilled water $(10 \mathrm{ml} / \mathrm{kg} \mathrm{BW})$ was orally given to control group rats. The tail blood flow was measured at $2 \mathrm{~h}$ before and $1 \mathrm{~h}$ after cooling. The level of tail blood flow at $2 \mathrm{~h}$ before cooling is set to $100 \%$. Data are shown as the means \pm SEM $(\mathrm{n}=10)$. "Denotes the significant difference compared with the control group $(\mathrm{P}<0.05)$. SAC, $S$-allylcysteine; SAMC, $S$-allylmercaptocysteine; S1PC, $S$-1-propenylcysteine.

AGE pretreatment had no significant effect on the tail blood flow of non-cooled rats (data not shown).

Effect of SIPC on NOx concentration in plasma. NO is known to trigger the vasodilation by initiating the signaling cascade (47). NO is a gas with a very short plasma half life of only a few seconds and thus its level is difficult to measure. It is a common practice to estimate the NO production by measuring its stable metabolites (NOx). As shown in Table II, the cooling of rat significantly $(\mathrm{P}<0.01)$ increased the plasma NOx concentration as indicated by the comparison between the two groups of rats with and without cold treatment. Moreover, pretreatment of rats with S1PC (6.5 mg/kg BW) further increased the plasma NOx level $(\mathrm{P}<0.05)$, compared to non-pretreated rats.

Effect of SIPC on eNOS and AMPK phosphorylation in aorta. Fig. 6 shows the effect of S1PC on the level of phosphorylated



Figure 4. The dose-dependent effect of S1PC pretreatment on the tail blood flow in cold-treated rats. S1PC was orally administered at the dose of 0.26 , 1.3 and $6.5 \mathrm{mg} / \mathrm{kg} \mathrm{BW}$ to male Wistar rats (14 weeks old) at $2 \mathrm{~h}$ before cold-treatment $\left(15^{\circ} \mathrm{C}, 10 \mathrm{~min}\right)$. Distilled water $(10 \mathrm{ml} / \mathrm{kg} \mathrm{BW})$ was given to control group rats. The tail blood flow was measured at $2 \mathrm{~h}$ before and $1 \mathrm{~h}$ after cooling. The level of tail blood flow $2 \mathrm{~h}$ before cooling is set to $100 \%$. Data are shown as the means \pm SEM $(n=9-10)$. "Denotes the significant difference compared with the control group $(\mathrm{P}<0.05)$. S1PC, $S$-1-propenylcysteine.



Figure 5. The effect of S1PC pretreatment on the tail blood flow in cold-treated rats. S1PC $(6.5 \mathrm{mg} / \mathrm{kg} \mathrm{BW})$ was orally administered to male Wistar rats at $2 \mathrm{~h}$ before cold-treatment $\left(15^{\circ} \mathrm{C}, 10 \mathrm{~min}\right)$. Distilled water $(10 \mathrm{ml} / \mathrm{kg} \mathrm{BW})$ was given to control group rats. The level of tail blood flow at $2 \mathrm{~h}$ before cooling is set to $100 \%$. Data are shown as the means \pm SEM $(n=9)$. * Denotes the significant difference compared with the control group $(\mathrm{P}<0.05)$. "\# Denotes the significant difference compared with the value before cooling $(\mathrm{P}<0.01)$. S1PC, $S$-1-propenylcysteine.

eNOS and AMPK in aorta that are key regulatory molecules of NO production in the vascular endothelium. By western blot analysis, the phosphorylation level of both eNOS and AMPK was found to be up-regulated by cooling. Additionally, pretreatment of rat with S1PC $(6.5 \mathrm{mg} / \mathrm{kg}$ BW $)$ significantly increased the phosphorylation of eNOS and AMPK compared to pretreatment with DW.

\section{Discussion}

AGE reportedly promotes the recovery of rectal temperature decline in mice induced by cooling, and its effect is more potent than that of raw or other garlic preparations (32). Recently it was reported that AGE and S1PC, a constituent of 


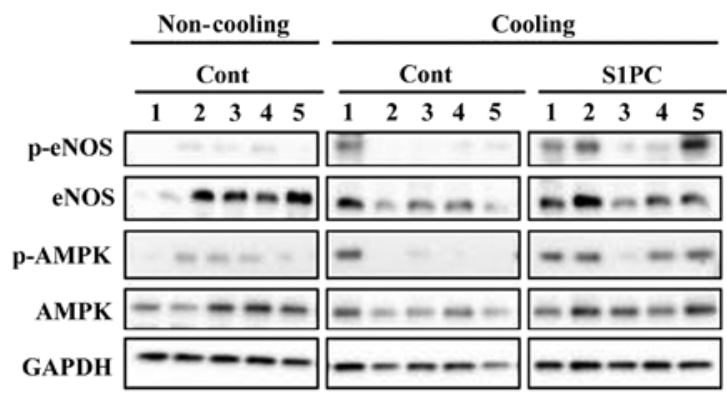

A



B

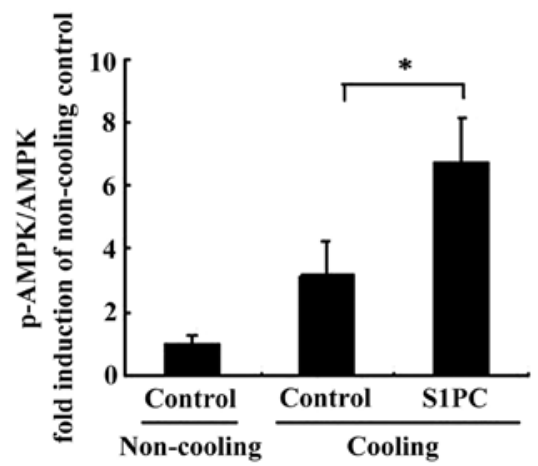

Figure 6. The effect of S1PC on the phosphorylation of eNOS and AMPK in the aorta of cold-treated rats. S1PC was orally administered at the dose of $6.5 \mathrm{mg} /$ $\mathrm{kg}$ BW to male Wistar rats $2 \mathrm{~h}$ before cold-treatment $\left(15^{\circ} \mathrm{C}, 10 \mathrm{~min}\right)$. Distilled water $(10 \mathrm{ml} / \mathrm{kg} \mathrm{BW})$ was given to control group rats. Total protein was extracted from the aorta $1 \mathrm{~h}$ after cooling. The level of phosphorylated eNOS and AMPK protein was analyzed by western blot analysis. The representative blot of immnoreactive bands was shown in the upper pannel. Lanes 1 to 5 represent five rats in each group. The level of phoshorylated eNOS (A) and AMPK (B) protein was quantitated and expressed relative to the level of GAPDH. Data are shown as the means \pm SEM $(\mathrm{n}=8-9) .{ }^{*}$ and ${ }^{* *}$ denote significant differences compared with the cooling control group ( $\mathrm{P}<0.05$ and $\mathrm{P}<0.01$, respectively). S1PC, $S$-1-propenylcysteine; eNOS, endothelial nitric oxide synthase; AMPK, AMP-activated protein kinase.

AGE, significantly increase the tail blood flow of SHR (21). At present, however, the underlying mechanism of AGE action has not been fully elucidated.

In this study, we examined the effects of AGE and its three characteristic sulfur compounds SAC, S1PC, and SAMC on the peripheral blood circulation by using a cold-treated rat model; the tail blood flow of rat was reduced by cooling, and the effect of pretreatment with AGE and these three constituents was examined in terms of the recovery of the decreased blood flow. We found that pretreatment with AGE or S1PC significantly counteracted the reduction of tail blood flow of the rat caused by cooling. The effect of S1PC is dose-dependent with the maximal dose of $6.5 \mathrm{mg} / \mathrm{kg} \mathrm{BW}$ and specific in the sense that other constituents of AGE, SAC and SAMC had no effect on the reduction of tail blood flow. These results suggested that S1PC is a major active constituent responsible for the effect of AGE to improve the peripheral blood circulation.

The skin blood flow is regulated by both the sympathetic vasoconstrictor system and nonadrenergic sympathetic active vasodilator system to maintain body temperature $(48,49)$. Under the cold conditions, the vasoconstriction of peripheral artery is induced by both activation of sympathetic reflex and reduction of locally produced NO (50), leading to poor circulation and low body temperature. In addition, Koganezawa et al (51) found that cooling of the rat skin stimulates presynaptic P2 purinoceptors on sympathetic nerve terminals and facilitates the release of noradrenaline, thereby inducing contraction of skin blood vessels via the activation of $\alpha 1$ - and $\alpha 2$-adrenoceptors. Thus it was conceivable that S1PC improves the blood flow of cooled rat by inhibiting noradrenaline signaling and/or the enhancement of NO production. However, Takashima et al (52) reported that S1PC had no effect on noradrenaline-induced contraction in isolated rat blood vessels. Thus it is more likely that S1PC improves the blood flow by acting on NO production system but not on the pathway of noradrenalin-triggered vasoconstriction.

The NO production system has a critical role for vasodilation; NO is produced by eNOS on vascular endothelium, that increases cGMP levels via activating soluble guanylyl cyclase present in smooth muscle cells and thereby causes vascular smooth muscle relaxation $(53,54)$. In addition, it was shown that NO was involved in the recovery of the reduced human skin blood flow after cooling (50). Furthermore, a previous study reported that the NO synthesis inhibitor, L-NAME, delayed the recovery of tail skin temperature of mice decreased by cooling (55). Previously, AGE was shown to increase NO production in endothelial cells $(52,56)$. In this study, the cooling of rats significantly increased the plasma NOx concentration (Table II). We also showed that additional pretreatment with S1PC further increased the concentration of NO metabolites in the plasma of cooled rats when compared to DW-pretreated control (Table II). These results suggested that S1PC improved the reduction of tail blood flow of cooled rats via enhancing NO production. It was reported that both low temperature and shear stress induce the activation of eNOS by activating 
AMPK $(57,58)$. AMPK is known to phosphorylate the specific serine residue (Ser1177) of eNOS that is essential for its activation $(58,59)$. It was also shown that AGE activated AMPK in both diabetic model TSOD mice (39), and arteriosclerotic model ApoE-KO mice (36). In addition, S1PC enhanced the AMPK activity in mouse spleen cells in vitro (37). In this study, the phosphorylation level of both eNOS and AMPK was up-regulated by cooling of rats (Fig. 6). The additional pretreatment with S1PC further increased the phosphorylation of eNOS and AMPK in the aorta of cooled rats, compared to DW-pretreated control (Fig. 6). On the other hand, S1PC did not affect the normal tail blood flow of non-cooled rats. These results suggest that S1PC enhances NO production induced by the low temperature and shear stress through the activation of AMPK, leading to improvement of peripheral circulatory disturbance.

In summary, this study showed that pretreatment with S1PC alleviated the cold-induced reduction of tail blood flow in rat by increasing the NOx concentration in plasma, and the phosphorylation of eNOS and AMPK in aorta. The findings suggest that S1PC may be a useful agent for the treatment of peripheral circulatory disorders including RP and poor circulation caused by smoking, aging, and stress.

\section{Acknowledgements}

The authors thank Dr Takami Oka of Wakunaga Pharmaceutical Co., Ltd. for his helpful advice, encouragement, and critical reading of the manuscript.

\section{Funding}

No funding was received.

\section{Availability of data and materials}

All data generated or analyzed during this study are included in this published article.

\section{Authors' contributions}

MU, KK, and JIS designed the experiments, and MU performed blood flow measurement, and was a major contributor in writing the manuscript. KK performed measurements of plasma NOx level. JIS performed measurements of vascular NO-related phosphorylation. All authors have read and approved the final manuscript.

\section{Ethics approval and consent to participate}

Animal experiments were approved by the Wakunaga Pharmaceutical Co., Ltd. Institutional Animal Care and Use Committee (approval no. 258). This investigation conformed to the Guide for the Care and Use of Laboratory Animals published by the US National Institute of Health (NIH Publication, 8th edition, 2011).

\section{Patient consent for publication}

Not applicable.

\section{Competing interests}

The authors declare that they have no competing interests.

\section{References}

1. Elam M and Wallin BG: Skin blood flow responses to mental stress in man depend on body temperature. Acta Physiol Scand 129: 429-431, 1987.

2. Liu C, Yavar Z and Sun Q: Cardiovascular response to thermoregulatory challenges. Am J Physiol Heart Circ Physiol 309: H1793-H1812, 2015.

3. LeRoy EC and Medsger TA Jr: Raynaud's phenomenon: A proposal for classification. Clin Exp Rheumatol 10: 485-488, 1992.

4. Lis-Święty A: Recent advances in the workup and management of Raynaud phenomenon. Pol Arch Intern Med 129: 798-808, 2019.

5. United States Pharmacopeial Convention I. United States Pharmacopoeia 38 Garlic Fluid Extract USP 28-NF 33. United States Pharmacopeial Convention, Rockville MD, pp6052-6055, 2015.

6. Colín-González AL, Santana RA, Silva-Islas CA, Chánez-Cárdenas ME, Santamaría A and Maldonado PD: The antioxidant mechanisms underlying the aged garlic extract- and S-allylcysteine-induced protection. Oxid Med Cell Longev 2012: 907162, 2012.

7. Matsutomo T and Kodera Y: Development of an analytic method for sulfur compounds in aged garlic extract with the use of a postcolumn high performance liquid chromatography method with sulfur-specific detection. J Nutr 146: 450S-455S, 2016.

8. Ried K, Frank OR and Stocks NP: Aged garlic extract lowers blood pressure in patients with treated but uncontrolled hypertension: A randomised controlled trial. Maturitas 67: 144-150, 2010.

9. Ried K, Frank OR and Stocks NP: Aged garlic extract reduces blood pressure in hypertensives: A dose-response trial. Eur J Clin Nutr 67: 64-70, 2013.

10. Ried K, Travica N and Sali A: The effect of aged garlic extract on blood pressure and other cardiovascular risk factors in uncontrolled hypertensives: The AGE at Heart trial. Integr Blood Press Control 9: 9-21, 2016.

11. Ried K, Travica N and Sali A: The effect of kyolic aged garlic extract on gut microbiota, inflammation, and cardiovascular markers in hypertensives: The GarGIC Trial. Front Nutr 5: 122. 2018.

12. Ried K: Garlic lowers blood pressure in hypertensive subjects, improves arterial stiffness and gut microbiota: A review and meta-analysis. Exp Ther Med 19: 1472-1478, 2020.

13. Budoff MJ, Ahmadi N, Gul KM, Liu ST, Flores FR, Tiano J, Takasu J, Miller E and Tsimikas S: Aged garlic extract supplemented with B vitamins, folic acid and L-arginine retards the progression of subclinical atherosclerosis: A randomized clinical trial. Prev Med 49: 101-107, 2009.

14. Matsumoto S, Nakanishi R, Li D, Alani A, Rezaeian P, Prabhu S, Abraham J, Fahmy MA, Dailing C, Flores F, et al: Aged garlic extract reduces low attenuation plaque in coronary arteries of patients with metabolic syndrome in a prospective randomized double-blind study. J Nutr 146: 427S-432S, 2016.

15. Gruenwald J, Bongartz U, Bothe G and Uebelhack R: Effects of aged garlic extract on arterial elasticity in a placebo-controlled clinical trial using EndoPAT ${ }^{\mathrm{TM}}$ technology. Exp Ther Med 19: $1490-1499,2020$

16. Gómez-Arbelóez D, Lahera V, Oubina P, Valero-Munoz M, Heras NL, Rodriguez Y, Garcia RG, Camacho PA and Lopez-jaramillo P: Aged garlic extract improves adiponectin levels in subjects with metabolic syndrome: A double-blind, placebo controlled, randomized, crossover study. Mediators Inflamm 285795: 2013, 2013.

17. Zini A, Mann J, Mazor S and Vered Y: The efficacy of aged garlic extract on gingivitis - a randomized clinical trial. J Clin Dent 29: 52-56, 2018.

18. Harauma A and Moriguchi T: Aged garlic extract improves blood pressure in spontaneously hypertensive rats more safely than raw garlic. J Nutr 136 (Suppl 3): 769S-773S, 2006.

19. Matsutomo T, Ushijima M, Kodera Y, Nakamoto M, Takashima M, Morihara N and Tamura K: Metabolomic study on the antihypertensive effect of S-1-propenylcysteine in spontaneously hypertensive rats using liquid chromatography coupled with quadrupole-Orbitrap mass spectrometry. J Chromatogr B Analyt Technol Biomed Life Sci 1046: 147-155, 2017. 
20. Matsutomo T, Ushijima $\mathbf{M}$, Kunimura $\mathrm{K}$ and Ohtani $\mathrm{M}$ : Metabolomic study reveals the acute hypotensive effect of $\mathrm{S}$-1-propenylcysteine accompanied by alteration of the plasma histidine level in spontaneously hypertensive rats. J Pharm Biomed Anal 168: 148-154, 2019.

21. Ushijima M, Takashima M, Kunimura K, Kodera Y, Morihara N and Tamura K: Effects of S-1-propenylcysteine, a sulfur compound in aged garlic extract, on blood pressure and peripheral circulation in spontaneously hypertensive rats. J Pharm Pharmacol 70: 559-565, 2018.

22. Matsutomo T: Potential benefits of garlic and other dietary supplements for the management of hypertension (Review). Exp Ther Med 19: 1479-1484, 2020.

23. Chuah SC, Moore PK and Zhu YZ: S-allylcysteine mediates cardioprotection in an acute myocardial infarction rat model via a hydrogen sulfide-mediated pathway. Am J Physiol Heart Circ Physiol 293: H2693-H2701, 2007.

24. Borek C: Antioxidant health effects of aged garlic extract. J Nutr 131 (Suppl 3): 1010S-1015S, 2001.

25. Yamato O, Tsuneyoshi T, Ushijima M, Jikihara $H$ and Yabuki A: Safety and efficacy of aged garlic extract in dogs: upregulation of the nuclear factor erythroid 2-related factor 2 (Nrf2) signaling pathway and Nrf2-regulated phase II antioxidant enzymes. BMC Vet Res 29: 14: 373, 2018.

26. Tsuneyoshi T: BACH1 mediates the antioxidant properties of aged garlic extract (Review). Exp Ther Med 19: 1500-1503, 2020

27. Moriguchi T, Saito H and Nishiyama N: Aged garlic extract prolongs longevity and improves spatial memory deficit in senescence-accelerated mouse. Biol Pharm Bull 19: 305-307, 1996.

28. Ogawa T, Kodera Y, Hirata D, Blackwell TK and Mizunuma M: Natural thioallyl compounds increase oxidative stress resistance and lifespan in Caenorhabditis elegans by modulating SKN-1/Nrf. Sci Rep 6: 21611, 2016.

29. Kyo E, Uda N, Kasuga S and Itakura Y: Immunomodulatory effects of aged garlic extract. J Nutr 131 (Suppl 3): 1075S-1079S, 2001.

30. Suzuki J, Yamaguchi T, Matsutomo T, Amano H, Morihara N and Kodera Y: S-1-Propenylcysteine promotes the differentiation of $\mathrm{B}$ cells into IgA-producing cells by the induction of Erk1/2-dependent Xbp1 expression in Peyer's patches. Nutrition 32: 884-889, 2016.

31. Suzuki J, Miki S, Ushijima M and Kodera Y: Regulation of immune response by $S$-1-propenylcysteine through autophagy-mediated protein degradation (Review). Exp Ther Med 19: 1570-1573, 2020

32. Ushijima M, Sumioka I, Kakimoto M, Yokoyama K, Uda N, Matsuura H, Kyo E, Suzuki A, Kasuga S, Itakura Y, et al: Effect of garlic and garlic preparations on physiological and psychological stress in mice. Phytother Res 11: 226-230, 1997.

33. Morihara N, Ushijima M, Kashimoto N, Sumioka I, Nishihama T, Hayama $\mathrm{M}$ and Takeda $\mathrm{H}$ : Aged garlic extract ameliorates physical fatigue. Biol Pharm Bull 29: 962-966, 2006.

34. Kasuga S, Ushijima M, Morihara N, Itakura $Y$ and Nakata $Y$ : Effect of aged garlic extract (AGE) on hyperglycemia induced by immobilization stress in mice] Nippon Yakurigaku Zasshi 114: 191-197, 1999 (In Japanese).

35. Kyo E, Uda N, Ushijima M, Kasuga S and Itakura Y: Prevention of psychological stress-induced immune suppression by aged garlic extract. Phytomedicine 6: 325-330, 1999.

36. Morihara N, Hino A, Miki S, Takashima M and Suzuki JI: Aged garlic extract suppresses inflammation in apolipoprotein E-knockout mice. Mol Nutr Food Res 61: 1700308, 2017.

37. Suzuki JI, Kodera Y, Miki S, Ushijima M, Takashima M, Matsutomo T and Morihara N: Anti-inflammatory action of cysteine derivative S-1-propenylcysteine by inducing MyD88 degradation. Sci Rep 8: 14148, 2018.

38. Ohtani $M$ and Nishimura T: Sulfur-containing amino acids in aged garlic extract inhibit inflammation in human gingival epithelial cells by suppressing intercellular adhesion molecule-1 expression and IL-6 secretion. Biomed Rep 12: 99-108, 2020

39. Miki S, Suzuki JI, Kunimura K and Morihara N: Mechanisms underlying the attenuation of chronic inflammatory diseases by aged garlic extract: Involvement of the activation of AMP-activated protein kinase (Review). Exp Ther Med 19: $1462-1467,2020$.

40. Nakagawa S, Kasuga $\mathrm{S}$ and Matsuura $\mathrm{H}$ : Prevention of liver damage by aged garlic extract and its components in mice. Phytother Res 3: 50-53, 1989.
41. Okuhara T: Clinical study of GE on peripheral circulation. Jpn Pharmacol Ther 22: 3695-3701, 1994.

42. Wlosinska M, Nilsson AC, Hlebowicz J, Malmsjö M, Fakhro M and Lindstedt S: Aged garlic extract preserves cutaneous microcirculation in patients with increased risk for cardiovascular diseases: A double-blinded placebo-controlled study. Int Wound J 16: 1487-1493, 2019.

43. Mizuno I, Sumioka I, Ushijima M, Yasuda K, Mouri Y, Mizuho O, Ogasawara K and Kyo E: Improvement of peripheral blood circulation in mouse and human with aged garlic extract preparation combined with ginseng, oriental bezoar, antler velvet, cuscuta seed and epimedium herb. Pharmacometrics 67: 371-378, 2004.

44. Guan J, Lin H, Xie M, Huang M, Zhang D, Ma S, Bian W, Zhan Q and Zhao G: Higenamine exerts an antispasmodic effect on cold-induced vasoconstriction by regulating the PI3K/Akt, ROS/ $22 \mathrm{C}-\mathrm{AR}$ and PTK9 pathways independently. Asian Pac J Trop Med 5: 935-938, 2012.

45. Ning SY, Jiang BP, Xu L, Fang TH and Wu MH: Effect of Liangxuehuayu Recipe on hemorheology in rats with blood stasis syndrome. Asian Pac J Trop Med 5: 935-938, 2012.

46. Ryan TJ and Copeman PW: Microvascular pattern and blood stasis in skin disease. Br J Dermatol 81: 563-573, 1969.

47. López-López JG, Pérez-Vizcaíno F, Cogolludo AL, Ibarra M, Zaragozá-Arnáez F and Tamargo J: Nitric oxide- and nitric oxide donors-induced relaxation and its modulation by oxidative stress in piglet pulmonary arteries. Br J Pharmacol 133: 615-624, 2001.

48. Johnson JM and Proppe DW: Cardiovascular adjustments to heat stress. In: Handbook of physiology. Section 4: Environmental physiology. Fregley MJ and Blatteis CM (eds). Oxford University Press, New York, NY, pp215-243, 1996.

49. Rowell LB: Human circulation: regulation during physical stress. Oxford University Press, New York, NY, 1986.

50. Thompson-Torgerson CS, Holowatz LA, Flavahan NA and Kenney WL: Cold-induced cutaneous vasoconstriction is mediated by Rho kinase in vivo in human skin. Am J Physiol Heart Circ Physiol 292: H1700-H1705, 2007.

51. Koganezawa T, Ishikawa T, Fujita Y, Yamashita T, Tajima T, Honda $\mathrm{M}$ and Nakayama K: Local regulation of skin blood flow during cooling involving presynaptic $\mathrm{P} 2$ purinoceptors in rats. $\mathrm{Br}$ J Pharmacol 148: 579-586, 2006

52. Takashima M, Kanamori Y, Kodera Y, Morihara N and Tamura K: Aged garlic extract exerts endothelium-dependent vasorelaxant effect on rat aorta by increasing nitric oxide production. Phytomedicine 24: 56-61, 2017.

53. Lindauer U, Megow D, Matsuda H and Dirnagl U: Nitric oxide: A modulator, but not a mediator, of neurovascular coupling in rat somatosensory cortex. Am J Physiol 277: H799-H811, 1999.

54. Hodges GJ, Traeger JA III, Tang T, Kosiba WA, Zhao K and Johnson JM: Role of sensory nerves in the cutaneous vasoconstrictor response to local cooling in humans. Am J Physiol Heart Circ Physiol 293: H784-H789, 2007.

55. Zhao Y, Vanhoutte PM and Leung SWS: Vascular nitric oxide: Beyond eNOS. J Pharmacol Sci 129: 83-94, 2015.

56. Morihara N, Sumioka I, Moriguchi T, Uda N and Kyo E: Aged garlic extract enhances production of nitric oxide. Life Sci 71: 509-517, 2002

57. Binti Md Isa K, Kawasaki N, Ueyama K, Sumii T and Kudo S: Effects of cold exposure and shear stress on endothelial nitric oxide synthase activation. Biochem Biophys Res Commun 412: 318-322, 2011.

58. Zhang Y, Lee TS, Kolb EM, Sun K, Lu X, Sladek FM, Kassab GS, Garland T Jr and Shyy JY: AMP-activated protein kinase is involved in endothelial NO synthase activation in response to shear stress. Arterioscler Thromb Vasc Biol 26: 1281-1287, 2006.

59. Zheng Q, Yuan Y, Yi W, Lau WB, Wang Y, Wang X, Sun Y, Lopez BL, Christopher TA, Peterson JM, et al: Clq/TNF-related proteins, a family of novel adipokines, induce vascular relaxation through the adiponectin receptor-1/AMPK/eNOS/nitric oxide signaling pathway. Arterioscler Thromb Vasc Biol 31: 2616-2623, 2011.

This work is licensed under a Creative Commons Attribution-NonCommercial-NoDerivatives 4.0 International (CC BY-NC-ND 4.0) License. 